\title{
Phase I clinical and pharmacokinetic study of sorafenib in combination with carboplatin and paclitaxel in patients with advanced non-small cell lung cancer
}

\author{
Isamu Okamoto • Masaki Miyazaki • Ryotaro Morinaga $\cdot$ Hiroyasu Kaneda • \\ Shinya Ueda • Yoshikazu Hasegawa • Taroh Satoh • Akira Kawada • \\ Masahiro Fukuoka • Koichi Fukino • Takahiko Tanigawa • Kazuhiko Nakagawa
}

Received: 7 August 2009 /Accepted: 2 September 2009 /Published online: 18 September 2009

(C) The Author(s) 2009. This article is published with open access at Springerlink.com

\begin{abstract}
Summary Objectives Unsatisfactory efficacy of current treatments for advanced lung cancer has prompted the search for new therapies, with sorafenib, a multikinase inhibitor, being one candidate drug. This phase I trial was conducted to evaluate drug safety and pharmacokinetics as well as tumor response of sorafenib in combination with paclitaxel and carboplatin in patients with advanced nonsmall cell lung cancer (NSCLC). Methods Eligible patients received paclitaxel $\left(200 \mathrm{mg} / \mathrm{m}^{2}\right)$ and carboplatin (area under the curve [AUC] of $6 \mathrm{mg} \mathrm{min} \mathrm{mL}^{-1}$ ) on day 1 and sorafenib (400 mg, twice daily) on days 2 through 19 of a 21-day cycle. Results Four of the initial six patients (cohort 1) experienced dose-limiting toxicities (DLTs), resulting in amendment of the treatment protocol. An additional seven patients (cohort 2) were enrolled, two of whom developed DLTs. DLTs included erythema multiforme, hand-foot skin reaction, and elevated plasma alanine aminotransferase in cohort 1 as well as gastrointestinal perforation at a site of metastasis and pneumonia
\end{abstract}

I. Okamoto $(\bowtie) \cdot$ M. Miyazaki $\cdot$ R. Morinaga $\cdot H$. Kaneda $\cdot$

S. Ueda $\cdot$ Y. Hasegawa $\cdot$ T. Satoh $\cdot$ M. Fukuoka $\cdot$ K. Nakagawa

Department of Medical Oncology,

Kinki University School of Medicine,

377-2 Ohno-higashi,

Osaka-Sayama, Osaka 589-8511, Japan

e-mail: chi-okamoto@dotd.med.kindai.ac.jp

A. Kawada

Department of Dermatology,

Kinki University School of Medicine,

Osaka-Sayama, Osaka, Japan

K. Fukino $\cdot$ T. Tanigawa

Bayer Yakuhin Ltd.,

Kita-ku, Osaka, Japan in cohort 2. Most adverse events were manageable. One complete and six partial responses were observed among the 12 evaluable patients. Coadministration of the three drugs had no impact on their respective pharmacokinetics. Conclusion The present study confirmed that sorafenib at $400 \mathrm{mg}$ once daily in combination with carboplatin AUC $5 \mathrm{mg} \mathrm{min} \mathrm{mL}^{-1}$ and paclitaxel $200 \mathrm{mg} / \mathrm{m}^{2}$ is feasible in Japanese patients with advanced NSCLC. The results of this study also showed that this combination therapy had encouraging antitumor activity and was not associated with relevant pharmacokinetic interaction in Japanese NSCLC patients.

Keywords Carboplatin · Lung cancer Paclitaxel · Pharmacokinetics $\cdot$ Safety $\cdot$ Sorafenib

\section{Introduction}

Non-small cell lung cancer (NSCLC) accounts for $\sim 75 \%$ of all lung cancers and is the most common cause of cancer-related deaths worldwide [1]. Individuals with metastatic NSCLC are candidates for palliative systemic chemotherapy that confers only a limited survival benefit $[2,3]$. The dismal outlook for patients with advanced NSCLC who receive currently available therapies has prompted a search for new, more effective chemotherapeutic agents and combination regimens. Target-based therapies are therefore being pursued as potential treatment alternatives.

Sorafenib (BAY 43-9006; Nexavar; Bayer HealthCare, Montville, NJ; Onyx Pharmaceuticals, Emeryville, CA), is an oral multikinase inhibitor that inhibits Raf serinethreonine kinases and several receptor tyrosine kinases 
that function in tumor growth and angiogenesis [4]. The Ras-Raf-MEK-ERK signaling pathway plays a pivotal role in the regulation of tumor cell growth by relaying signals from the cell surface to the nucleus, with the components of this pathway, including Raf, thus representing potential targets for anticancer treatment $[5,6]$. Sorafenib also targets the vascular endothelial growth factor (VEGF) receptors VEGFR-2 and VEGFR-3 as well as platelet-derived growth factor receptor- $\beta$ (PDGFR- $\beta$ ), the ligands for which (VEGF and PDGF) are proangiogenic factors essential for tumor growth and metastasis [4]. Sorafenib has recently been approved for treatment of advanced renal cell carcinoma and hepatocellular carcinoma in the United States, Europe, and several other countries. Furthermore, sorafenib is currently undergoing clinical evaluation for a variety of additional cancers, including NSCLC.

Although several phase I clinical trials of sorafenib alone or in combination with other drugs have been conducted [7-19], no such phase I study for a specific type of lung cancer has been performed. The aim of the present phase I study was to evaluate the safety and pharmacokinetics of sorafenib in combination with carboplatin and paclitaxel in patients with advanced NSCLC.

\section{Patients and methods}

\section{Patient selection}

Eligible patients were 18 years of age or older with unresectable NSCLC, as confirmed histologically or cytologically, and with a life expectancy of at least 12 weeks. They were required to be naïve to chemotherapy and to have an Eastern Cooperative Oncology Group performance status of 0 or 1 . The eligibility criteria also included adequate bone marrow, hepatic, and renal function as well as normal blood coagulation parameters. Individuals were excluded if they had previous or concurrent cancer distinct in primary site or histology from NSCLC or any cancer curatively treated $>3$ years prior to study entry; clinically active or significant cardiovascular disease; human immunodeficiency virus infection, chronic hepatitis $\mathrm{B}$ or $\mathrm{C}$, or other serious infections; a seizure disorder requiring medication; a history of organ allograft, substance abuse, or medical, psychological, or social conditions that might interfere with participation in the study; or allergy to the study treatment. Pregnant or breast-feeding patients were also excluded. All patients received information regarding the nature and purpose of the study, and they provided written informed consent in accordance with institutional guidelines. The study protocol was approved by the Institutional Review Board of Kinki University Hospital.
Study design

The study was designed as a single-center, open-label, nonplacebo-controlled phase I trial to define the safety, tolerability, pharmacokinetics, and tumor response profile of sorafenib administered according to a dosing schedule of 18 days on and 3 days off and in combination with paclitaxel and carboplatin chemotherapy in chemonaïve patients with advanced NSCLC. The other phase I trial of sorafenib in combination with paclitaxel and carboplatin had already confirmed the safety of sorafenib $400 \mathrm{mg}$ twice daily in combination with paclitaxel at $225 \mathrm{mg} / \mathrm{m}^{2}$ and carboplatin at area under the curve [AUC] of $6 \mathrm{mg} \mathrm{min}$ $\mathrm{mL}^{-1}$ in a dose-escalation manner [16]. Based on this result, the starting doses of the present study were decided as follows; Paclitaxel $\left(200 \mathrm{mg} / \mathrm{m}^{2}\right.$, infused over $\left.3 \mathrm{~h}\right)$ and carboplatin (AUC $6 \mathrm{mg} \mathrm{min} \mathrm{mL}^{-1}$ during infusion for $30 \mathrm{~min}$ ) were administered consecutively on day 1 , and sorafenib (400 mg, twice daily) was administered for 18 days starting on day 2. There was a concern that sorafenib may inhibit cytochrome P450 enzymes responsible for the clearance of paclitaxel. Based on this possible pharmacokinetic interaction and antagonistic effects, sorafenib administration was discontinued for two days (days 20 and 21) before the next administration of paclitaxel in both the present study and the other phase I trial [16]. This treatment cycle was repeated every 21 days until unacceptable toxicity, tumor progression, or death occurred. Carboplatin-paclitaxel chemotherapy was not allowed to exceed six cycles, after which sorafenib administration could continue until the occurrence of intolerable toxicity, disease progression. If fewer than two of the first six patients experienced dose limiting toxicity (DLT) in the first cycle, the dose level was to be recommended for subsequent clinical trials and an additional six patients were to be enrolled to the cohort.

\section{Patient evaluation}

All observations pertinent to the safety of sorafenib were recorded, including results of physical examinations, vital signs, adverse events, use of concomitant medications, and laboratory test data. Patients were routinely monitored for adverse events, which were recorded with severity and relation to study medication according to the National Cancer Institute (NCI) Common Terminology Criteria for Adverse Events (CTCAE) version 3.0. Assessment of the chest and abdomen for tumors was performed radiologically (computed tomography or magnetic resonance imaging) according to the Response Evaluation Criteria in Solid Tumors (RECIST) [20]. The same radiological method was performed to maintain consistency of evaluation. Patients for whom antitumor efficacy (complete or partial response) 
was observed or who had stable disease were continuously treated according to the study protocol. Measurements were repeated in patients with a complete or partial response at a time more than 4 weeks after the response criteria were first met in order to confirm tumor response according to RECIST.

\section{Pharmacokinetics}

To investigate the effect of paclitaxel-carboplatin on the pharmacokinetics of sorafenib, we collected blood samples on days 2 and 19 of treatment cycle 1 for cohort 1 and determined the plasma concentration of sorafenib. On both days, samples were collected at $0 \mathrm{~h}$ (pre-morning dose of sorafenib); at $0.5,1,3,6$, and $12 \mathrm{~h}$ (pre-evening dose); and at $24 \mathrm{~h}$ (pre-morning dose on day 3). After dosing on day 19, additional samples were collected at 48 and $72 \mathrm{~h}$ (before infusion of paclitaxel in cycle 2). The evening dose of sorafenib was not administered on day 19 of cycle 1 for the purpose of pharmacokinetic sampling. As a result of amendment to the treatment protocol for cohort 2, a modified schedule of blood sampling was adopted. For determination of the plasma concentration of sorafenib, blood samples were collected at the same time points in cycle 2 as in cycle 1 , with the exception that the blood sample obtained at $12 \mathrm{~h}$ after the morning administration of sorafenib on day 2 was collected before the evening dose on day 2 in cohort 2. The concentration of sorafenib in plasma samples was determined with the use of a validated high-performance liquid chromatography-tandem mass spectrometry (LC-MS/MS) assay.

To investigate the effects of sorafenib on the pharmacokinetics of paclitaxel and carboplatin, we collected blood samples on day 1 of cycle 1 for cohort 1 and determined the plasma concentrations of carboplatin, paclitaxel, and the paclitaxel metabolite 6-hydroxy-paclitaxel. Samples were collected at $0 \mathrm{~h}, 1.5 \mathrm{~h}$ (during paclitaxel infusion), $3 \mathrm{~h}$ (within $5 \mathrm{~min}$ before completion of paclitaxel infusion), $3.5 \mathrm{~h}$ (within $5 \mathrm{~min}$ before completion of carboplatin infusion), as well as 4, 5, 7, 11, 24, and $48 \mathrm{~h}$. The amended treatment protocol for cohort 2 was accommodated by collection of blood samples immediately before, $1.5 \mathrm{~h}$ after the start of, within $5 \mathrm{~min}$ before completion of, as well as $0.5,1,2,4,8,21$, and $45 \mathrm{~h}$ after completion of paclitaxel infusion on day 1 of cycles 1,2 , and 3 for paclitaxel, and immediately before, within 5 min before completion of, as well as $0.5,1,3,7,20,31$, and $44 \mathrm{~h}$ after completion of carboplatin infusion on day 1 of cycles 1,2 , and 3 for carboplatin. The plasma concentrations of free (unbound) platinum derived from carboplatin, of paclitaxel, and of 6hydroxy-paclitaxel were measured with the use of atomic absorption spectrophotometry and were validated by LCMS/MS assays.
Pharmacokinetic parameters, including the AUC, maximum concentration $\left(C_{\max }\right)$, and elimination half-life $\left(t_{1 / 2}\right)$, for sorafenib, paclitaxel, and carboplatin were calculated by noncompartment analysis as previously described [17].

\section{Results}

Patient demographics

A total of 13 chemonaïve patients with advanced NSCLC was enrolled in the study, six in cohort 1 and seven in cohort 2. The baseline demographics for all patients are shown in Table 1. Histological diagnosis revealed that the most common histology was adenocarcinoma (eight patients, or $61.5 \%$ ), followed by large cell carcinoma and squamous cell carcinoma (each with two patients, or $15.4 \%)$.

\section{DLT}

Table 2 summarizes the dosing regimens for evaluated cohorts together with DLTs. The first six patients enrolled in cohort 1 were treated with $400 \mathrm{mg}$ of sorafenib twice daily (days 2 to 19) combined with paclitaxel at $200 \mathrm{mg} / \mathrm{m}^{2}$ and carboplatin at an AUC of $6 \mathrm{mg} \mathrm{min} \mathrm{mL}^{-1}$ (30-min infusion). Four of these six patients experienced DLTs during the first cycle of treatment (two with erythema

Table 1 Patient demographics

No. of patients

\begin{tabular}{ll}
\hline Total enrolled & 13 \\
Cohort 1 & 6 \\
Cohort 2 & 7 \\
Age (years) & \\
Median & 66 \\
Range & $41-76$ \\
Sex & \\
Male & 9 \\
Female & 4 \\
ECOG performance status & \\
0 & 4 \\
1 & 9 \\
Disease stage & \\
IV & 13 \\
Histology & \\
Adenocarcinoma & 8 \\
Large cell carcinoma & 2 \\
Squamous cell carcinoma & 2 \\
Undifferentiated carcinoma & 1 \\
\hline
\end{tabular}

ECOG Eastern Cooperative Oncology Group 
Table 2 Observed DLTs according to dose level

\begin{tabular}{|c|c|c|c|c|c|c|}
\hline Cohort & $\begin{array}{l}\text { Paclitaxel } \\
\left(\mathrm{mg} / \mathrm{m}^{2}\right)\end{array}$ & $\begin{array}{l}\text { Carboplatin } \\
\left(\text { mgminmL }^{-1}\right)\end{array}$ & $\begin{array}{l}\text { Sorafenib } \\
(\mathrm{mg})\end{array}$ & $\begin{array}{l}\text { No. of } \\
\text { patients }\end{array}$ & $\begin{array}{l}\text { No. of patients } \\
\text { with DLTs }\end{array}$ & DLTs \\
\hline 1 & 200 & 6 & 400 twice daily & 6 & 4 & $\begin{array}{l}\text { Erythema multiforme, grade } 3(n=2) \\
\text { Hand-foot skin reaction, grade } 3(n=1) \\
\text { ALT elevation, grade } 3(n=1)\end{array}$ \\
\hline 2 (cycle 1) & 200 & 5 & 400 once daily & 7 & 0 & None \\
\hline 2 (cycle 2) & 200 & 5 & 400 twice daily & 7 & 2 & $\begin{array}{l}\text { Perforation, GI, small bowel NOS, } \\
\text { grade } 3(n=1) \\
\text { Infection-lung (pneumonia) } \\
\text { of grade } 3 \text { with neutrophil of grade } 4(n=1)\end{array}$ \\
\hline
\end{tabular}

$D L T S$ dose-limiting toxicities, $A L T$ alanine aminotransferase, GI gastrointestinal, NOS not otherwise specified

multiforme of grade 3 , one with a hand and foot skin reaction of grade 3 , and one with elevation of plasma alanine aminotransferase [ALT] of grade 3). One of the patients diagnosed with erythema multiforme developed a rash of grade 1 on the arms, thigh, and hip on day 5; by day 15 , the rash had spread to the entire body with development of pruritus (grade 3), and histopathologic analysis of skin biopsy specimens revealed superficial dermal vasodilation as well as perivascular lymphocyte and plasma cell infiltration, consistent with erythema multiforme (Fig. 1a, b). The second patient also developed a localized rash of grade 1 that appeared in the right lower part of the abdomen on day 5 and had spread to the entire body with the development of a high fever on day 12; histopathologic analysis of skin biopsy specimens again supported a diagnosis of erythema multiforme. Both patients responded well to steroid therapy and improved.

Given that the incidence of DLT at the adopted dose level exceeded that predefined for the maximum tolerated dose, a modified dose level consisting of $400 \mathrm{mg}$ of sorafenib once daily (days 2 to 19) combined with paclitaxel at $200 \mathrm{mg} / \mathrm{m}^{2}$ and carboplatin at an AUC of $5 \mathrm{mg} \mathrm{min} \mathrm{mL}^{-1}$ (60-min infusion) was evaluated for the seven additional patients of cohort 2. None of these seven patients experienced DLT during cycle 1. Intrapatient escalation of sorafenib dose was allowed if the patient did not experience DLT in cycle 1 of cohort 2; the dose of sorafenib was thus increased to $400 \mathrm{mg}$ twice daily from day 2 to day 19 in subsequent courses. Among the seven patients who received sorafenib at $400 \mathrm{mg}$ twice daily combined with paclitaxel $\left(200 \mathrm{mg} / \mathrm{m}^{2}\right)$ and carboplatin (AUC of $5 \mathrm{mg} \mathrm{min} \mathrm{mL}^{-1}$ ), two individuals developed DLT: one a perforation of the small bowel of grade 4 and one pneumonia of grade 3 . The patient with gastrointestinal perforation, who had metastases in the left adrenal gland and small intestine, developed abdominal pain, fever, and peritonitis 26 days after initiation of sorafenib at $400 \mathrm{mg}$ twice daily and required emergency surgery. He recovered after surgery, and pathological examination of the surgical specimen confirmed the presence of tumor cells at the site of perforation. Given the marked tumor response of the patient on radiographic examination, the perforation event was likely associated with the antitumor effect of the study treatment.

Safety

All 13 enrolled patients were evaluable for safety analysis. Treatment-emergent adverse events (Table 3) occurred in all patients, the most common being hematologic or dermatologic in nature, sensory neuropathy, anorexia, and nausea. Neutropenia of grade 4 occurred in nine (69\%) patients (four in cohort 1 and five in cohort 2). Hand-foot skin reaction occurred in five patients (three in cohort 1 and two in cohort 2), hypertension in four patients (two in cohort 1 and two in cohort 2), elevated plasma lipase in four patients (three in cohort 1 and one in cohort 2), and erythema multiforme in three patients (two in cohort 1 and one in cohort 2).

\section{Antitumor activity}

Tumor response was evaluated in 12 of the 13 patients (Fig. 2), with the remaining patient in cohort 2 not being available for assessment of such response. One patient in cohort 1 had a confirmed complete response, and six patients (three in each cohort) had a confirmed partial response; the overall response rate was thus 58\% $(95 \%$ confidence interval of 28 to $85 \%$ ). Five patients, two in cohort 1 and three in cohort 2, had stable disease. Cavitation of lung lesions was observed in one patient (Fig. 1c, d). The median time to disease progression was 5.7 months $(95 \%$ confidence interval of 4.3 to 20.1 months). 


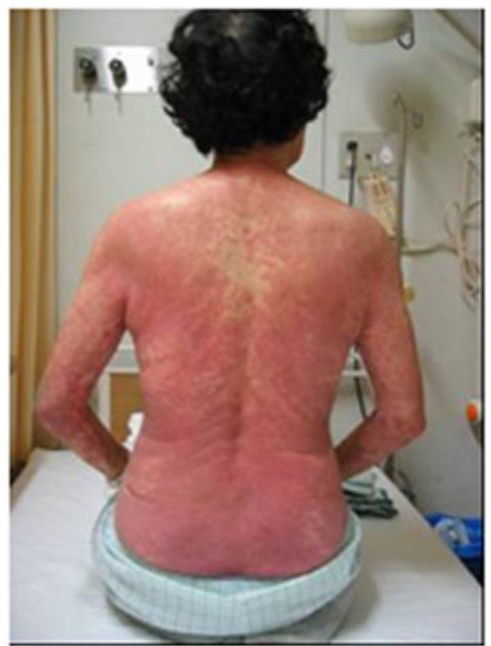

C

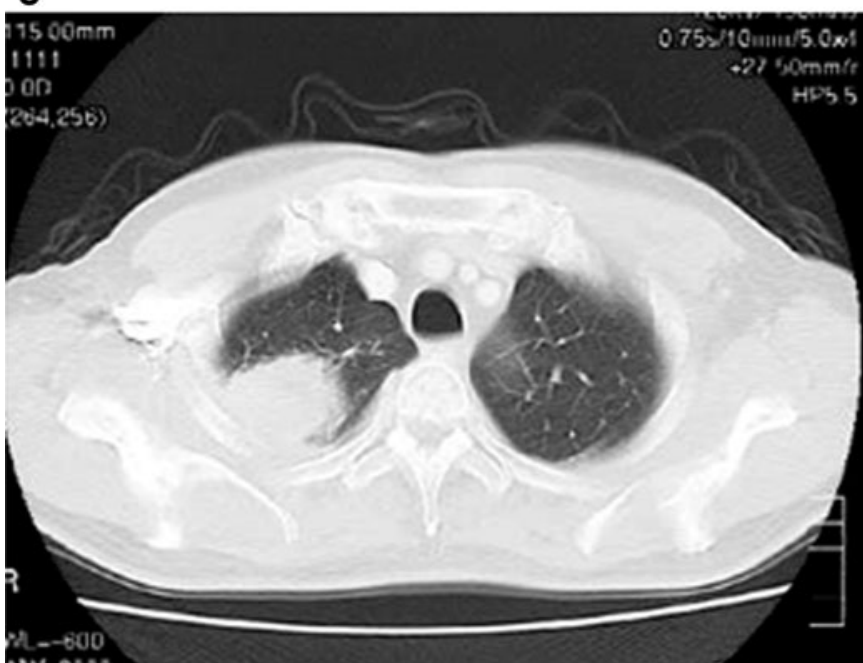

Fig. 1 Development of erythema multiforme and tumor cavitation in patients with advanced NSCLC treated with sorafenib in combination with carboplatin-paclitaxel. a A rash, initially localized to the arms, thigh, and hip, spread to the entire body. b Hematoxylin-eosin staining of a skin lesion from the patient shown in (a) revealed infiltration of inflammatory cells, mostly lymphocytes, around superficial dermal

\section{Pharmacokinetics}

Pharmacokinetic analysis for sorafenib in the presence of paclitaxel and carboplatin (Table 4) was based on the patients in cohort 1 (cycle 1) and cohort 2 (cycles 1 and 2) after administration of a single dose (day 2) or multiple doses (day 19). The increases in mean $C_{\max }$ from days 2 to 19 were consistent with those in mean $\mathrm{AUC}_{0-12}$, likely reflecting the long mean $t_{1 / 2}$ (20.4 to $26.8 \mathrm{~h}$ on day 19$)$. In cohort 2 , the increases in the mean values of $\mathrm{AUC}_{0-12}$ and $C_{\max }$ in cycle 2 (400 $\mathrm{mg}$, twice daily) compared with those in cycle 1 (400 mg, once daily) were consistent with the increase in sorafenib dosing. At steady state, after multiple b

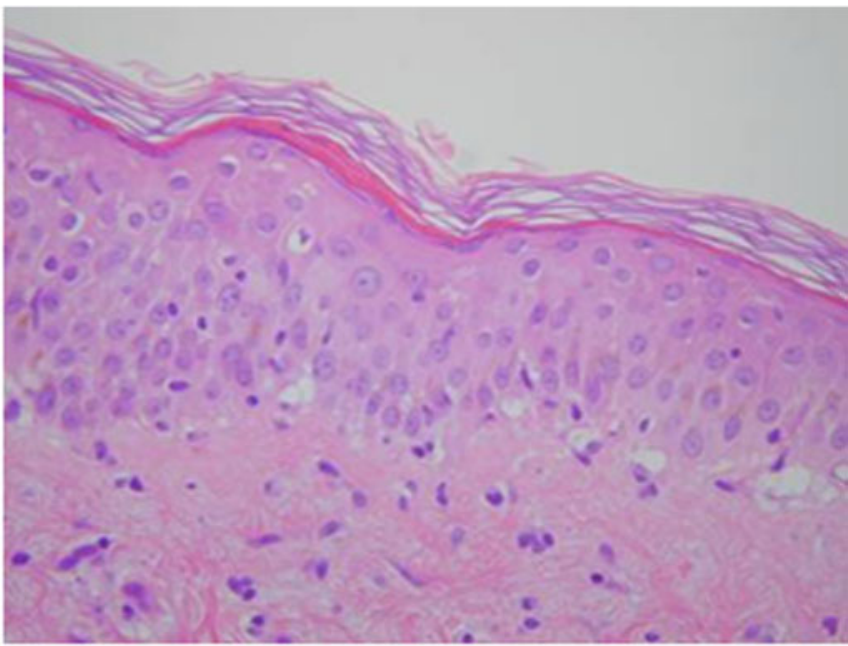

d

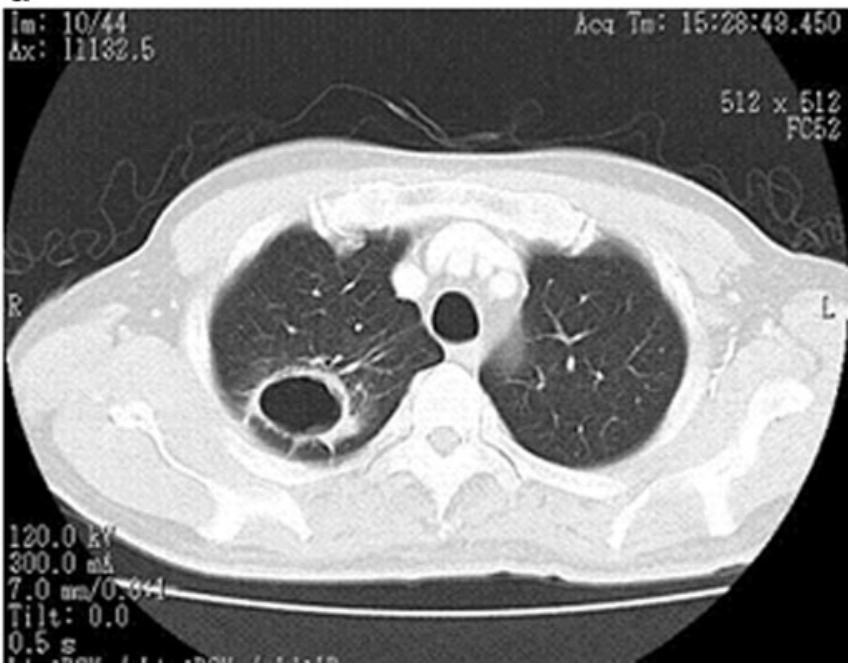

blood vessels and the epidermal-dermal junction. Liquefaction degeneration in basal epidermal layers and cavernous transformation in part of the epidermal squamous cell layer were also observed. c, d Computed tomography revealed a solid tumor without cavitation in the right lung of a patient at baseline (c), whereas the same tumor showed marked central cavitation on day 19 of cycle 1 (d)

administrations of sorafenib at $400 \mathrm{mg}$ twice daily together with paclitaxel and carboplatin, the mean values of $\mathrm{AUC}_{0-12}$ and $C_{\max }$ in cohort 1 (cycle 1, day 19) were $31.3 \mathrm{mg} \mathrm{h} \mathrm{L}^{-1}$ and $4.6 \mathrm{mg} / \mathrm{L}$, respectively, and those in cohort 2 (cycle 2 , day 19) were $39.1 \mathrm{mg} \mathrm{h} \mathrm{L}^{-1}$ and $5.9 \mathrm{mg} / \mathrm{L}$, respectively.

Given that treatment was discontinued after cycle 1 in four of the six patients in cohort 1 , the effects of multiple doses of sorafenib on the pharmacokinetics of paclitaxel and carboplatin were evaluated in cohort 2. Pharmacokinetic analysis for paclitaxel and carboplatin was performed during cycle 1 before sorafenib administration and during cycles 2 and 3 after sorafenib administration (Table 4). Small increases in the mean AUC and $C_{\max }$ values for 
Table 3 Numbers of patients with treatment-emergent adverse events including those with a CTCAE worst grade of 3 or 4

\begin{tabular}{|c|c|c|c|c|c|c|c|}
\hline \multirow[t]{4}{*}{ Event category } & \multirow[t]{4}{*}{ CTCAE term } & \multirow{2}{*}{\multicolumn{3}{|c|}{$\begin{array}{l}\text { Cohort } 1 \\
(n=6)\end{array}$}} & \multicolumn{3}{|c|}{ Cohort 2} \\
\hline & & & & & $(n=7)$ & & \\
\hline & & \multicolumn{3}{|c|}{ CTCAE grade } & \multicolumn{3}{|c|}{ CTCAE grade } \\
\hline & & Any & 3 & 4 & Any & 3 & 4 \\
\hline Allergy/immunology & Allergic reaction & 2 & & & 2 & & 1 \\
\hline \multirow[t]{5}{*}{ Blood/bone marrow } & Hemoglobin & 2 & & & 5 & 3 & \\
\hline & Leukocytes & 5 & 4 & & 6 & 3 & 1 \\
\hline & Lymphopenia & 2 & 2 & & 5 & 3 & 1 \\
\hline & Neutrophils & 5 & & 4 & 7 & & 5 \\
\hline & Platelets & 3 & & & 5 & 2 & 1 \\
\hline Cardiac, general & Hypertension & 2 & & & 2 & 1 & \\
\hline Constitutional symptoms & Weight loss & 1 & & & 4 & 1 & \\
\hline \multirow[t]{3}{*}{ Dermatology/skin } & Erythema multiforme & 2 & 2 & & 1 & & \\
\hline & Hand-foot skin reaction & 3 & 1 & & 2 & & \\
\hline & Rash/desquamation & 4 & & & 5 & & \\
\hline \multirow[t]{4}{*}{ Gastrointestinal } & Anorexia & 5 & & & 6 & 3 & \\
\hline & Dehydration & & & & 2 & 1 & \\
\hline & Nausea & 4 & & & 5 & 1 & \\
\hline & Perforation, GI, small bowel NOS & & & & 1 & & \\
\hline \multirow[t]{2}{*}{ Infection } & Febrile neutropenia & 1 & 1 & & & & \\
\hline & Infection with G4 neutrophils, lung (pneumonia) & & & & 1 & 1 & \\
\hline \multirow[t]{6}{*}{ Metabolic/laboratory } & ALT & 3 & 1 & 1 & 1 & & \\
\hline & AST & 2 & 1 & & 1 & & \\
\hline & Hypokalemia & & & & 1 & 1 & \\
\hline & Hyponatremia & & & & 2 & 2 & \\
\hline & Hypophosphatemia & 4 & 2 & & & & \\
\hline & Lipase & 3 & 2 & & 1 & & \\
\hline \multirow[t]{2}{*}{ Neurology } & Neuropathy, motor & & & & 1 & 1 & \\
\hline & Neuropathy, sensory & 4 & & & 6 & 2 & \\
\hline Pulmonary/upper respiratory & Dyspnea & 1 & & & 1 & 1 & \\
\hline
\end{tabular}

CTCAE Common Terminology Criteria for Adverse Events, GI gastrointestinal, NOS not otherwise specified, $A L T$ alanine aminotransferase, $A S T$ aspartate aminotransferase

Fig. 2 Tumor response. Ten of the 12 evaluable patients showed tumor shrinkage, with one individual manifesting a complete response $(-100 \%)$

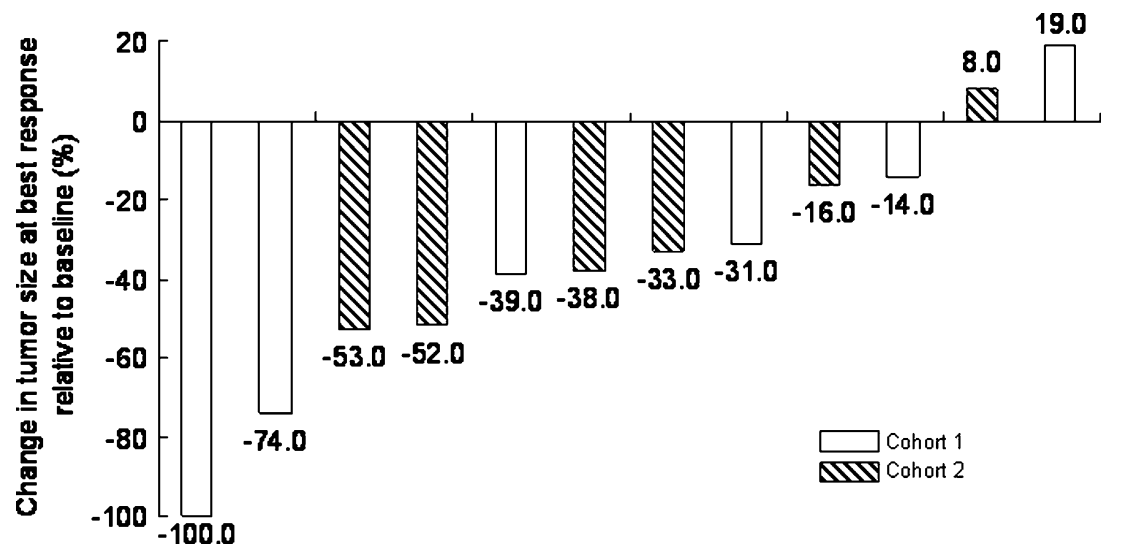


Table 4 Pharmacokinetic analysis

\begin{tabular}{|c|c|c|c|c|c|c|}
\hline \multirow[t]{3}{*}{ Sorafenib } & \multicolumn{2}{|l|}{ Cohort 1} & \multicolumn{4}{|l|}{ Cohort 2} \\
\hline & Cycle 1 & & Cycle 1 & & Cycle 2 & \\
\hline & $\begin{array}{l}\text { Day } 2 \\
\qquad 400 \mathrm{mg} \mathrm{sd} \\
(n=6)\end{array}$ & $\begin{array}{l}\text { Day } 19 \\
\quad 400 \mathrm{mg} \text { bid } \\
(n=3)\end{array}$ & $\begin{array}{l}\text { Day } 2 \\
\quad 400 \mathrm{mg} \mathrm{sd} \\
(n=7)\end{array}$ & $\begin{array}{l}\text { Day } 19 \\
\quad 400 \mathrm{mg} \text { od } \\
(n=7)\end{array}$ & $\begin{array}{l}\text { Day } 2 \\
\qquad 400 \mathrm{mg} \mathrm{sd} \\
(n=6)\end{array}$ & $\begin{array}{l}\text { Day } 19 \\
\quad 400 \mathrm{mg} \text { bid } \\
(n=4)\end{array}$ \\
\hline $\begin{array}{l}\mathrm{AUC}_{0-12} \\
\quad\left(\mathrm{mg} \mathrm{h} \mathrm{L}^{-1}\right)\end{array}$ & $18.2(74)$ & $31.3(32)$ & $9.0(82)$ & $24.4(25)$ & $14.6(25)$ & $39.1(51)$ \\
\hline$C_{\max }(\mathrm{mg} / \mathrm{L})$ & $2.5(96)$ & $4.6(36)$ & $1.2(93)$ & $3.2(22)$ & $2.0(21)$ & $5.9(38)$ \\
\hline$t_{1 / 2}(\mathrm{~h})$ & & $20.4(18)$ & & $26.8(41)$ & & $23.9(29)$ \\
\hline \multirow[t]{2}{*}{ Paclitaxel } & \multicolumn{6}{|l|}{ Cohort 2} \\
\hline & \multicolumn{2}{|l|}{ Cycle $1(n=7)$} & \multicolumn{2}{|l|}{ Cycle $2(n=6)$} & \multicolumn{2}{|l|}{ Cycle $3(n=4)$} \\
\hline $\operatorname{AUC}\left(\mathrm{mg} \mathrm{h} \mathrm{L}{ }^{-1}\right)$ & \multirow{2}{*}{\multicolumn{2}{|c|}{27889.1}} & \multicolumn{2}{|l|}{$29538.6(23)$} & \multicolumn{2}{|l|}{$34712.8(51)$} \\
\hline Ratio $[90 \% \mathrm{CI}]$ & & & \multicolumn{2}{|l|}{$1.05[0.88-1.25]$} & \multicolumn{2}{|l|}{$1.26[1.02-1.55]$} \\
\hline$C_{\max }(\mathrm{mg} / \mathrm{L})$ & \multicolumn{2}{|l|}{$8016.5(53)$} & \multicolumn{2}{|l|}{$10076.4(18)$} & \multicolumn{2}{|l|}{$11218.8(65)$} \\
\hline Ratio $[90 \% \mathrm{CI}]$ & & & \multicolumn{2}{|l|}{$1.19[0.80-1.77]$} & \multicolumn{2}{|l|}{$1.39[0.88-2.21]$} \\
\hline$t_{1 / 2}(\mathrm{~h})$ & \multicolumn{2}{|l|}{$10.7(10)$} & $11.1(6)$ & & \multicolumn{2}{|l|}{$11.4(3)$} \\
\hline \multirow[t]{2}{*}{ Free platinum } & \multicolumn{6}{|l|}{ Cohort 2} \\
\hline & \multicolumn{2}{|l|}{ Cycle $1(n=7)$} & \multicolumn{2}{|l|}{ Cycle $2(n=6)$} & \multicolumn{2}{|l|}{ Cycle $3(n=4)$} \\
\hline $\begin{array}{l}\text { AUC (mg } \\
\left.\mathrm{h} \mathrm{L}^{-1}\right)\end{array}$ & \multirow{2}{*}{\multicolumn{2}{|c|}{$44.9(23)$}} & \multicolumn{2}{|l|}{$44.4(25)$} & \multicolumn{2}{|l|}{$38.5(10)$} \\
\hline Ratio $[90 \% \mathrm{CI}]$ & & & \multicolumn{2}{|l|}{$1.00[0.91-1.10]$} & \multicolumn{2}{|l|}{$0.90[0.80-1.00]$} \\
\hline$C_{\max }(\mathrm{mg} / \mathrm{L})$ & \multirow{2}{*}{\multicolumn{2}{|c|}{$17.5(36)$}} & \multicolumn{2}{|l|}{$17.4(34)$} & \multicolumn{2}{|l|}{$17.5(9)$} \\
\hline Ratio $[90 \% \mathrm{CI}]$ & & & \multicolumn{2}{|l|}{$0.92[0.82-1.02]$} & \multicolumn{2}{|l|}{$0.97[0.85-1.11]$} \\
\hline
\end{tabular}

Pharmacokinetic parameters are presented as geometric means (\% coefficient of variation). Ratios for AUC and $C_{\max }$ values of paclitaxel and free platinum are dose-adjusted ratios in cycles 2 or 3 relative to those in cycle 1

$s d$ single dose, od once daily, bid twice daily, $C I$ confidence interval

paclitaxel were observed with progress of the cycles; however, these changes were not significant based on the inclusion of 1.00 in the $90 \%$ confidence interval for the ratio of AUC or $C_{\max }$ in cycles 2 or 3 to the corresponding value in cycle 1 . Similar results were obtained for 6hydroxy-paclitaxel (data not shown). There were also no significant differences in the mean AUC or $C_{\max }$ values of free platinum when standard chemotherapy was administered with or without sorafenib.

\section{Discussion}

We have investigated the effects of sorafenib, an oral multikinase inhibitor, in combination with standard chemotherapy (paclitaxel and carboplatin) in chemonaïve individuals with advanced NSCLC. Our results show that sorafenib can be integrated with the combination of paclitaxel and carboplatin. In the present study, the dose of carboplatin had to be capped one dose level lower (AUC of $5 \mathrm{mg} \mathrm{min} \mathrm{mL}^{-1}$ ) than is typical for administration of paclitaxel and carboplatin alone, because four out of six patients developed DLTs in cohort 1.

Two of the patients with DLTs in cohort 1 experienced erythema multiforme of grade 3. Previous studies have reported that most patients receiving sorafenib as monotherapy manifested dermatologic toxicities, mostly of grade 1 or 2 , including rash or desquamation (18 to $66 \%$ ), handfoot syndrome ( 25 to $62 \%$ ), and alopecia (18 to $53 \%$ ) [15, $21,22]$. Erythema multiforme was reported to occur in only 0.1 to $<1 \%$ of patients $[22,23]$. In the two cases of erythema multiforme in the present study, skin rashes occurred within a week after initiation of sorafenib treatment and spread to the entire body without organ dysfunction. Histopathologic examination of skin specimens supported the diagnosis of erythema multiforme. Steroid treatment and discontinuation of sorafenib resulted in marked improvement of the patients within days. A drug lymphocyte stimulation test was performed for both patients, with the results being positive for sorafenib and 
negative for both paclitaxel and carboplatin, suggesting that the exanthematous rashes were caused by drug allergy to sorafenib rather than by dose-dependent toxicity. Indeed, serious erythema multiforme was not observed in any of the seven patients in cohort 2 , for whom sorafenib was administered at $400 \mathrm{mg}$ twice daily in cycle 2 and subsequent cycles. The only differences between the treatment regimen in cohort 1 and that of cycle 2 and subsequent cycles in cohort 2 were the dose (AUC) and infusion time of carboplatin, which were $6 \mathrm{mg} \mathrm{min} \mathrm{mL}^{-1}$ over $30 \mathrm{~min}$ and $5 \mathrm{mg} \operatorname{min~} \mathrm{mL}^{-1}$ over $60 \mathrm{~min}$, respectively, and pharmacokinetic analysis revealed that the triplet regimen had no significant effects on the pharmacokinetics of the individual agents. These data thus suggest that the sorafenib-related erythema multiforme observed in cohort 1 was likely the result of classic skin hypersensitivity to the drug.

Two additional DLTs (hand-foot skin reaction and elevation of ALT, both of grade 3) were observed in cohort 1 , both of which were manageable and resolved by treatment interruption and remedial therapy. Although the study treatment was discontinued after the first cycle in the four patients with DLTs in cohort 1, one patient showing a partial response received three cycles of carboplatin-paclitaxel-sorafenib and an additional 13 cycles of sorafenib maintenance monotherapy, and another patient showing a complete response received four cycles of the combination therapy and an additional 23 cycles of sorafenib monotherapy. A previous phase I study of sorafenib combined with paclitaxel and carboplatin for advanced solid tumors (mostly malignant melanoma) recommended doses for future trials of sorafenib at $400 \mathrm{mg}$ twice daily, carboplatin at an AUC of $6 \mathrm{mg} \mathrm{min} \mathrm{mL}^{-1}$, and paclitaxel at $225 \mathrm{mg} / \mathrm{m}^{2}$. In a recently completed randomized phase III study of advanced NSCLC, patients were randomly assigned to treatment either with sorafenib at $400 \mathrm{mg}$ twice daily plus carboplatin (AUC of $6 \mathrm{mg} \mathrm{min}$ $\left.\mathrm{mL}^{-1}\right)$ and paclitaxel $\left(200 \mathrm{mg} / \mathrm{m}^{2}\right)$ or with carboplatin and paclitaxel alone [24]. The present study suggests that the dose of sorafenib tolerated by Japanese patients is likely to be lower than that tolerated by Western patients when this agent is combined with standard doses of carboplatin and paclitaxel.

We examined the pharmacokinetics of paclitaxel, carboplatin, and sorafenib in order to detect any relevant drug-drug interactions. The pharmacokinetics of sorafenib in the present combination study were similar to those described in previous monotherapy $[7$, 17] and combination [16] trials, in which there was no evidence of drug-drug interactions. Neither of the carboplatin doses administered in the present study (AUC of 5 or $6 \mathrm{mg} \mathrm{min} \mathrm{mL}^{-1}$ ) appeared to affect the pharmacokinet- ics of sorafenib. Furthermore, we have shown for the first time that administration of sorafenib at $400 \mathrm{mg}$ twice daily had no effect on the pharmacokinetics of carboplatin. Whereas small increases in the AUC and $C_{\max }$ values of paclitaxel and 6-hydroxy-paclitaxel were observed after sorafenib administration at $400 \mathrm{mg}$ twice daily, these increases were not statistically significant. Paclitaxel is primarily metabolized in the liver by the CYP2C8 pathway to 6-hydroxy-paclitaxel and is also metabolized by CYP3A4 [25]. Although we are not able to exclude possible inhibition by sorafenib of the metabolic clearance of paclitaxel, the observed increase in paclitaxel exposure was not associated with increased clinical toxicity. Together, our pharmacokinetic results suggest that concomitant administration of sorafenib, carboplatin, and paclitaxel had no significant impact on the pharmacokinetics of any of these three drugs in this treatment schedule, although our finding on pharmacokinetics will need to be reproduced in larger cohort of patients treated with this combination.

Although tumor evaluation was not the primary objective of our study, the combination treatment yielded promising results, with one complete response and six partial responses observed among the 12 evaluable patients. Despite this substantial antitumor activity observed in the present study, a phase III trial (ESCAPE: Evaluation of Sorafenib, Carboplatin, and Paclitaxel Efficacy) of 926 patients with advanced NSCLC receiving first-line therapy with paclitaxel and carboplatin in the absence or presence of sorafenib failed to show an improvement in efficacy with the addition of sorafenib to the standard combination chemotherapy [24]. Indeed, a subset analysis of the 219 patients with squamous histology was suggestive of a detrimental effect of sorafenib inclusion. The complete response and all partial responses in our phase I study occurred in patients with non-squamous NSCLC. Although the biological basis for a possible ethnic difference in sorafenib efficacy and toxicity remains unknown, further investigation are warranted to identify the patients who are more likely to benefit from this agent.

In conclusion, in combination with carboplatin AUC $5 \mathrm{mg} \mathrm{min} \mathrm{mL}^{-1}$ and paclitaxel $200 \mathrm{mg} / \mathrm{m}^{2}$, administration of sorafenib at $400 \mathrm{mg}$ once daily was confirmed to be feasible in Japanese patients with advanced NSCLC. There was no relevant pharmacokinetic interaction and the observed antitumor activity was encouraging in this study.

Funding This research was sponsored by Bayer Yakuhin Ltd.

Conflicts of interest Two of the co-authors, Koichi Fukino and Takahiko Tanigawa, are employees of Bayer Yakuhin Ltd. 
Open Access This article is distributed under the terms of the Creative Commons Attribution Noncommercial License which permits any noncommercial use, distribution, and reproduction in any medium, provided the original author(s) and source are credited.

\section{References}

1. Jemal A, Siegel R, Ward E, Hao Y, Xu J, Murray T, Thun MJ (2008) Cancer statistics, 2008. CA Cancer J Clin 58:71-96. doi:10.3322/CA.2007.0010

2. The American Society of Clinical Oncology (1997) Clinical practice guidelines for the treatment of unresectable nonsmall-cell lung cancer. Adopted on May 16, 1997 by the American Society of Clinical Oncology. J Clin Oncol 15:2996-3018

3. Socinski MA, Crowell R, Hensing TE, Langer CJ, Lilenbaum R, Sandler AB, Morris D, American College of Chest Physicians (2007) Treatment of non-small cell lung cancer, stage IV: ACCP evidence-based clinical practice guidelines (2nd edition). Chest 132(3 Suppl):277S-289S. doi:10.1378/chest.07-1381

4. Wilhelm SM, Carter C, Tang L, Wilkie D, McNabola A, Rong H, Chen C, Zhang X, Vincent P, McHugh M, Cao Y, Shujath J, Gawlak S, Eveleigh D, Rowley B, Liu L, Adnane L, Lynch M, Auclair D, Taylor I, Gedrich R, Voznesensky A, Riedl B, Post LE, Bollag G, Trail PA (2004) BAY 43-9006 exhibits broad spectrum oral antitumor activity and targets the RAF/MEK/ERK pathway and receptor tyrosine kinases involved in tumor progression and angiogenesis. Cancer Res 64:7099-7109. doi:10.1158/0008-5472. CAN-04-1443

5. Downward J (2003) Targeting RAS signalling pathways in cancer therapy. Nat Rev Cancer 3:11-22. doi:10.1038/nrc969

6. McCubrey JA, Steelman LS, Chappell WH, Abrams SL, Wong EW, Chang F, Lehmann B, Terrian DM, Milella M, Tafuri A, Stivala F, Libra M, Basecke J, Evangelisti C, Martelli AM, Franklin RA (2007) Roles of the Raf/MEK/ERK pathway in cell growth, malignant transformation and drug resistance. Biochim Biophys Acta 1773:1263-1284. doi:10.1016/j.bbamcr.2006.10.001

7. Strumberg D, Richly H, Hilger RA, Schleucher N, Korfee S, Tewes M, Faghih M, Brendel E, Voliotis D, Haase CG, Schwartz B, Awada A, Voigtmann R, Scheulen ME, Seeber S (2005) Phase I clinical and pharmacokinetic study of the novel Raf kinase and vascular endothelial growth factor receptor inhibitor BAY 43-9006 in patients with advanced refractory solid tumors. J Clin Oncol 23:965-972. doi:10.1200/JCO.2005.06.124

8. Clark JW, Eder JP, Ryan D, Lathia C, Lenz HJ (2005) Safety and pharmacokinetics of the dual action Raf kinase and vascular endothelial growth factor receptor inhibitor, BAY 43-9006, in patients with advanced, refractory solid tumors. Clin Cancer Res 11:5472-5480. doi:10.1158/1078-0432.CCR-04-2658

9. Awada A, Hendlisz A, Gil T, Bartholomeus S, Mano M, de Valeriola D, Strumberg D, Brendel E, Haase CG, Schwartz B, Piccart M (2005) Phase I safety and pharmacokinetics of BAY 43-9006 administered for 21 days on/7 days off in patients with advanced, refractory solid tumours. Br J Cancer 92:1855-1861. doi:10.1038/sj.bjc.6602584

10. Moore M, Hirte HW, Siu L, Oza A, Hotte SJ, Petrenciuc O, Cihon F, Lathia C, Schwartz B (2005) Phase I study to determine the safety and pharmacokinetics of the novel Raf kinase and VEGFR inhibitor BAY 43-9006, administered for 28 days on/7 days off in patients with advanced, refractory solid tumors. Ann Oncol 16:1688-1694. doi:10.1093/annonc/mdi310
11. Kupsch P, Henning BF, Passarge K, Richly H, Wiesemann K, Hilger RA, Scheulen ME, Christensen O, Brendel E, Schwartz B, Hofstra E, Voigtmann R, Seeber S, Strumberg D (2005) Results of a phase I trial of sorafenib (BAY 43-9006) in combination with oxaliplatin in patients with refractory solid tumors, including colorectal cancer. Clin Colorectal Cancer 5:188-196. doi:10.3816/ CCC.2005.n.030

12. Richly H, Henning BF, Kupsch $\mathrm{P}$, Passarge $\mathrm{K}$, Grubert $\mathrm{M}$, Hilger RA, Christensen O, Brendel E, Schwartz B, Ludwig M, Flashar C, Voigtmann R, Scheulen ME, Seeber S, Strumberg D (2006) Results of a Phase I trial of sorafenib (BAY 43-9006) in combination with doxorubicin in patients with refractory solid tumors. Ann Oncol 17:866-873. doi:10.1093/annonc/md1017

13. Siu LL, Awada A, Takimoto $\mathrm{CH}$, Piccart M, Schwartz B, Giannaris T, Lathia C, Petrenciuc O, Moore MJ (2006) Phase I trial of sorafenib and gemcitabine in advanced solid tumors with an expanded cohort in advanced pancreatic cancer. Clin Cancer Res 12:144-151. doi:10.1158/1078-0432.CCR-05-1571

14. Escudier B, Lassau N, Angevin E, Soria JC, Chami L, Lamuraglia M, Zafarana E, Landreau V, Schwartz B, Brendel E, Armand JP, Robert C (2007) Phase I trial of sorafenib in combination with IFN alpha-2a in patients with unresectable and/or metastatic renal cell carcinoma or malignant melanoma. Clin Cancer Res 13:1801-1809. doi:10.1158/1078-0432.CCR06-1432

15. Strumberg D, Clark JW, Awada A, Moore MJ, Richly H, Hendlisz A, Hirte HW, Eder JP, Lenz HJ, Schwartz B (2007) Safety, pharmacokinetics, and preliminary antitumor activity of sorafenib: a review of four phase I trials in patients with advanced refractory solid tumors. Oncologist 12:426-437. doi:10.1634/theoncologist.12-4-426

16. Flaherty KT, Schiller J, Schuchter LM, Liu G, Tuveson DA, Redlinger M, Lathia C, Xia C, Petrenciuc O, Hingorani SR, Jacobetz MA, Van Belle PA, Elder D, Brose MS, Weber BL, Albertini MR, O'Dwyer PJ (2008) A phase I trial of the oral, multikinase inhibitor sorafenib in combination with carboplatin and paclitaxel. Clin Cancer Res 14:4836-4842. doi:10.1158/10780432.CCR-07-4123

17. Minami H, Kawada K, Ebi H, Kitagawa K, Kim YI, Araki K, Mukai H, Tahara M, Nakajima H, Nakajima K (2008) Phase I and pharmacokinetic study of sorafenib, an oral multikinase inhibitor, in Japanese patients with advanced refractory solid tumors. Cancer Sci 99:1492-1498. doi:10.1111/j.1349-7006.2008.00837.x

18. Furuse J, Ishii H, Nakachi K, Suzuki E, Shimizu S, Nakajima K (2008) Phase I study of sorafenib in Japanese patients with hepatocellular carcinoma. Cancer Sci 99:159-165. doi:10.1111/ j.1349-7006.2007.00648.x

19. Takimoto CH, Awada A (2008) Safety and anti-tumor activity of sorafenib (Nexavar) in combination with other anti-cancer agents: a review of clinical trials. Cancer Chemother Pharmacol 61:535548. doi:10.1007/s00280-007-0639-9

20. Therasse P, Arbuck SG, Eisenhauer EA, Wanders J, Kaplan RS, Rubinstein L, Verweij J, Van Glabbeke M, van Oosterom AT, Christian MC, Gwyther SG (2000) New guidelines to evaluate the response to treatment in solid tumors. European Organization for Research and Treatment of Cancer, National Cancer Institute of the United States, National Cancer Institute of Canada. J Natl Cancer Inst 92:205-216. doi:10.1093/jnci/ 92.3.205

21. Strumberg D, Awada A, Hirte H, Clark JW, Seeber S, Piccart P, Hofstra E, Voliotis D, Christensen O, Brueckner A, Schwartz B (2006) Pooled safety analysis of BAY 43-9006 (sorafenib) monotherapy in patients with advanced solid tumours: Is rash associated with treatment outcome? Eur J Cancer 42:548-556. doi:10.1016/j.ejca.2005.11.014 
22. Robert C, Mateus C, Spatz A, Wechsler J, Escudier B (2009) Dermatologic symptoms associated with the multikinase inhibitor sorafenib. J Am Acad Dermatol 60:299-305. doi:10.1016/j. jaad.2008.06.034

23. MacGregor JL, Silvers DN, Grossman ME, Sherman WH (2007) Sorafenib-induced erythema multiforme. J Am Acad Dermatol 56:527-528. doi:10.1016/j.jaad.2006.10.981

24. Scagliotti G, von Pawel J, Reck M, Cupit L, Cihon F, DiMatteo S, O'Leary J, Hanna N (2008) Sorafenib plus carboplatin/paclitaxel in chemonaive patients with stage IIIB-IV non-small cell lung cancer: Interim analysis results from the phase III, randomized, double-blind, placebo-controlled, ESCAPE (Evaluation of Sorafenib, Carboplatin, and Paclitaxel efficacy in NSCLC) trial. J Thoracic Oncol 3(Suppl 1):S97-S98

25. Sonnichsen DS, Liu Q, Schuetz EG, Schuetz JD, Pappo A, Relling MV (1995) Variability in human cytochrome P450 paclitaxel metabolism. J Pharmacol Exp Ther 275:566575 